\title{
ELIA M2016, NUEVA VARIEDAD DE TRIGO HARINERO PARA RIEGO RESTRINGIDO EN EL BAJÍO, MÉXICO
}

\section{ELIA M2016, NEW BREAD WHEAT VARIETY FOR RESTRICTED IRRIGATION IN EL BAJIO, MEXICO}

\section{Ernesto Solís-Moya*, Julio Huerta-Espino², Héctor E. Villaseñor-Mir², Luis A. Mariscal-Amaro ${ }^{1}$, Lourdes Ledesma-Ramírez ${ }^{1}$ y Patricia Pérez-Herrera ${ }^{2}$}

\author{
'Instituto Nacional de Investigaciones Forestales, Agrícolas y Pecuarias (INIFAP), Campo Experimental Bajío, Celaya, Guanajuato, México. ${ }^{2} I N I F A P$, \\ Campo Experimental Valle de México, Coatlinchán, Texcoco, Estado de México, México. \\ *Autor para correspondencia (solis.ernesto@inifap.gob.mx)
}

En la región de El Bajío un factor que ha afectado la producción de trigo (Triticum spp.) de riego en los últimos 15 años es la poca disponibilidad de agua en las presas, lo que ha provocado que la superficie sembrada durante este periodo haya fluctuado entre 82,912 y 193,966 ha. El programa de trigo del Instituto Nacional de Investigaciones Forestales Agrícolas y Pecuarias (INIFAP) con sede en el Campo Experimental Bajío (CEBAJ) en Celaya, Guanajuato ha evaluado desde 1992 líneas sobresalientes de trigo bajo calendarios de dos, tres y cuatro riegos, incluido el riego de siembra. En el material segregante se ha practicado selección en forma alternada con tres y cuatro riegos. Esta estrategia de selección ha permitido identificar nuevos genotipos con mayor potencial de rendimiento bajo riego restringido (dos y tres riegos totales), entre ellos la nueva variedad de trigo harinero Elia M2016.

Las características morfológicas de las plantas de Elia M2016 fueron registradas en los ciclos 0-I de 2013 a 2015 con base en los descriptores de la Unión Internacional para la Protección de las Obtenciones Vegetales (UPOV, 2017). La variedad Elia M2016 obtuvo el número de registro definitivo TRI 163230217 y el título de obtentor 1700 en 2017 quedando registrada en el Catálogo Nacional de Variedades Vegetales (CNVV) del Servicio Nacional de Inspección y Certificación de Semillas por parte del INIFAP y protegida hasta el 18 de mayo del 2032.

Elia M2016 es de hábito de primavera; fue obtenida en el Programa de Mejoramiento Genético de Trigo del INIFAP en el CEBAJ, por hibridación y selección a través del método de mejoramiento genético masal, partiendo de una cruza entre los progenitores COLIBRI/TRAGOPAN, cuyo número de cruza e historia de selección es TR07CS22324C-OC-OR-2CSE-OR-0C. Las generaciones segregantes se sembraron en Celaya, Guanajuato $(R)$ durante el ciclo otoño invierno en condiciones de riego y en Texcoco, Estado de México (C), durante el ciclo primavera verano en condiciones de temporal. Desde el ciclo 2011-2012 se empezó a evaluar en ensayos de rendimiento en el CEBAJ, y en los ciclos 2012-2013, 2013-2014 y 2014-2015 en calendarios de dos, tres y cuatro riegos a los 0-55, 0-45-75 y 0-45-75-100 días después de siembra. En los mismos ciclos se evaluó en cinco fechas de siembra desde el 15 de noviembre hasta el 15 de enero, con intervalos de 15 días.

Elia M2016 también fue evaluada en 14 localidades en los ciclos de 2013-2014 a 2016-2017. En el ciclo 2013-2014 se evaluó en Presa de Uribe, Abasolo Gto. y Colorado de Herrera, Pénjamo Gto.; en 2014-2015 en Cruces de Rojas, Pénjamo, Gto., Guarapo, Valle de Santiago, Gto., Huipana, Pastor Ortíz, Michoacán, El Nacimiento, Manuel Doblado, Gto. y Puroagua, Jerécuaro, Gto.; en el ciclo 2015-2016 en La Estación, Pénjamo Gto., Loma de Flores, Salamanca, Gto. y Las Raíces, Valle de Santiago Gto.; en el ciclo 2016 2017 en Presa de Uribe, Abasolo, Gto., El Chiflido, Pénjamo, Gto., Cárdenas, Salamanca Gto. y Guarapo, Valle de Santiago, Gto., para un total de 13 parcelas en Guanajuato y una en Michoacán.

La variedad Elia M2016 es de hábito de crecimiento de primavera, semi-enana, de $90 \mathrm{~cm}$ de altura (Figura 1); su ciclo vegetativo es intermedio, con 77 días a floración y 130 días a madurez fisiológica. El tallo de Elia M2016 es fuerte, hueco, de color crema y moderadamente resistente al acame. La espiga es de color claro, piramidal, laxa, con barbas, tiene una longitud de 11 a $14 \mathrm{~cm}$ y produce de 20 a 24 espiguillas. Las glumas son de color blanco, de pico medio $(7.4 \mathrm{~mm})$, de forma ligeramente curva. La forma predominante del hombro es recta de ancho medio. La extensión de la vellosidad interna de la gluma es débil. El grano es de color blanco, de forma ovoide, bordes redondeados, con respuesta tenue al fenol.

Elia M2016 posee los genes de resistencia de raza específica a la roya de la hoja ( $L r) L r 7, L r 9, L r 10, L r 76, L r 77$, 


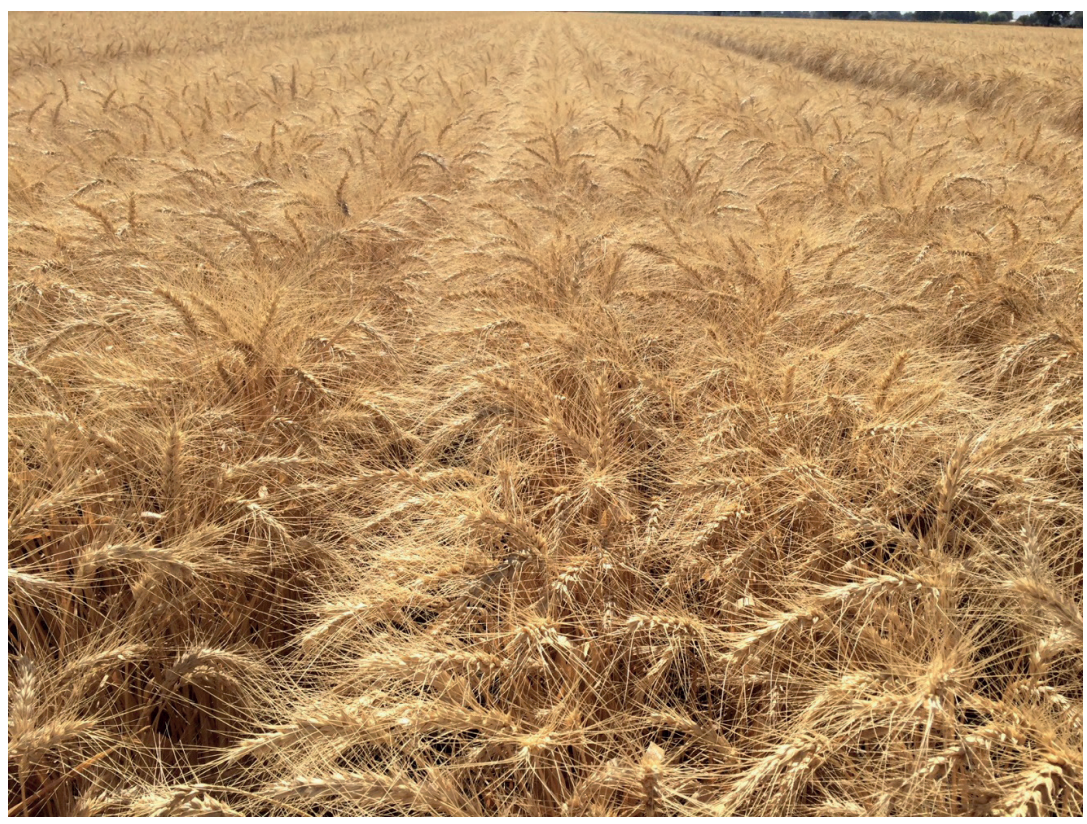

Figura 1. Aspecto de planta en campo de la variedad ELIA M2016.

Lr23 y $27+37$. Estos genes son efectivos en estado de plántula a las razas CBJ/QB, CBJ/QL, CBJ/QQ (HuertaEspino y Singh, 1994), LCJ/BN, BBG/BP, TCT/QB, TBD/ $T M, T C B / T D, M C J / Q M$ y MFB/SP, respectivamente (Singh, 1991). En planta adulta, la resistencia de Elia M2016 se basa en la acción del gen $L r 9$, que es de raza específica, y del gen $L$ r46 localizado en el cromosoma 1BL e inicialmente identificado en la variedad Pavón F76 (Singh et al., 1998). Se determinó la presencia de Lr46 mediante el marcador molecular csLV46G22 de tipo CAPS (Ponce-Molina et al., 2018).

Los bajos grados de severidad registrados en la variedad Elia M2016 en campo (menores de 30 \%) cuando se realizan inoculaciones artificiales con los aislamientos CEVAMEX14.25, MEX14.191 y MEX14.146, que combinan virulencia para los genes Yr2, Yr3, Yr6, Yr7, Yr8, Yr9, Yr77, Yr27 y Yr37 entre otros, indican que la nueva variedad basa su resistencia a roya lineal en por lo menos tres genes de patogenia lenta de la roya en planta adulta (Singh et al., 2000); uno de ellos, el gen Yr29, ligado al gen de roya de la hoja Lr46, es efectivo contra todas las razas de roya amarilla que existen en México (William et al. 2003).

El rendimiento de la nueva variedad en fechas de siembra (FS), calendarios de riegos (CR) y en las 14 localidades antes mencionadas en los ciclos 2013-2014 a 2016-2017 fue de 6,559,6,621 y 6,460 kg ha-1, respectivamente. En FS Elia M2016 superó a Luminaria F2012, Salamanca S75, Bárcenas S2002, Cortazar S94, Maya S2007, Urbina S2002 y Alondra F2014 por 33, 30, 19, 19, 18, 16 y $10 \%$, respectivamente. Bajo riego restringido (2 y 3 riegos), Elia M2016 las superó por 17, 30, 18.1, 18.6, 18.8, 11.7 y 7.2 $\%$. En localidades del Bajío, Elia M2016 fue superior por 23.6, 17.4, 9.7, 17.2, 13.5, 11.3, 9.7\%, respectivamente en relación con los testigos ya mencionados.

El peso hectolítrico promedio, índice de perlado y contenido de proteína en grano de Elia M2016 fueron de $76 \mathrm{~kg} \mathrm{hL}^{-1}, 44 \%$ y $12.2 \%$, respectivamente. La masa obtenida de la harina de Elia M2016 presenta una fuerza promedio del gluten de $208 \times 10^{-4} \mathrm{~J}$, lo que permite caracterizar a la variedad como un trigo de gluten medio fuerte. Elia M2016 presenta un valor promedio de índice $\mathrm{P} / \mathrm{L}$ (tenacidad/extensibilidad) de 1.0, que corresponde a un gluten balanceado. Las harinas de Elia M2016 presentan un volumen promedio de pan de $750 \mathrm{~mL}$. El factor galletero de la nueva variedad Elia M2016 (4.5) fue igual o superior al de las variedades testigo Urbina S2007 (4.5), Bárcenas S2002 (4.5) y Maya S2007 (4.1); por lo que al igual que las variedades de gluten débil, puede ser empleada en galletería, así como en repostería. Elia M2016 presenta gluteninas de alto peso molecular (GAPM) donde predominan las subunidades Glu A1 2*, Glu B1 $17+18$ y Glu D1 $2+12$, que se han asociado a trigos de gluten débil y medio fuerte.

La semilla básica de Elia M2016 está disponible desde diciembre de 2017 en el INIFAP - Campo Experimental Bajío para su venta a las compañías productoras de semilla que lo soliciten. 


\section{AGRADECIMIENTOS}

Al Grupo Bimbo S. A. de C. V. por el financiamiento del proyecto "Mejoramiento genético para la obtención de variedades de trigo de gluten fuerte y débil con alta calidad industrial, para la región del Bajío, México". Así mismo, al CONACYT por el financiamiento al proyecto CONACYTSAGARPA-COFUPRO "Sistema de mejoramiento genético para generar variedades de trigo resistentes a royas, de alto rendimiento y alta calidad para una producción sustentable en México".

\section{BIBLIOGRAFÍA}

Huerta-Espino J. and R. P. Singh (1994) First report of virulence to wheat with leaf rust resistance gene Lr19 in Mexico. Plant Disease 78:640, https://doi.org/10.1094/PD-78-0640C

Ponce-Molina L. J., J. Huerta-Espino, R. P. Singh, B. R. Basnet, E. Lagudah, V. H. Aguilar-Rincón, G. Alvarado, R. Lobato-Ortiz, J. García-Zavala and C. Lan (2018) Characterization of adult plant resistance to leaf rust and stripe rust in Indian wheat cultivar 'New Pusa 876'. Crop Science 58:630-638, https://doi.org/10.2135/ cropsci2017.06.0396

Singh R. P. (1991) Pathogenicity variations of Puccinia recondita $f$. sp. tritici and $P$. graminis $f$. sp. tritici in wheat-growing areas of Mexico during 1988 and 1989. Plant Disease 75:790-794 https://doi.org/10.1094/PD-75-0790

Singh R. P., A. Mujeeb-Kazi and J. Huerta-Espino (1998) Lr46: a gene conferring slow-rusting resistance to leaf rust in wheat. Phytopathology 88:890-894, https://doi.org/10.1094/ PHYTO.1998.88.9.890

Singh R. P., J. Huerta-Espino and S. Rajaram (2000) Achieving nearimmunity to leaf and stripe rusts in wheat by combining slow rusting resistance genes. Acta Phytopathologica et Entomologica Hungarica 35:133-139.

UPOV, International Union for the Protection of New Varieties of Plants (2017) Guidelines for the conduct of tests for distinctness, homogeneity and stability. Wheat (Triticum aestivum L. emend. Fiori et Paol). International Union for the Protection of New Varieties of Plants. Geneva, Switzerland. $39 p$.

William M., R. P. Singh, J. Huerta-Espino, S. Ortiz Islas and D. Hoisington (2003) Molecular marker mapping of leaf rust resistance gene Lr46 and its association with stripe rust resistance gene Yr29 in wheat. Phytopathology 93:153-159, https://doi.org/10.1094/ PHYTO.2003.93.2.153 
